\title{
Determination of Sequencing Batch Reactor (SBR) Performance in Treatment of Composting Plant Leachate
}

\author{
Hassan Hashemi, ${ }^{1}$ Tahereh Jasemi Zad, ${ }^{2}$ Zahra Derakhshan, ${ }^{2}$ and Ali Asghar Ebrahimi ${ }^{2,}{ }^{*}$ \\ ${ }^{1}$ Research Center for Health Sciences, Shiraz University of Medical Sciences, Shiraz, Iran \\ ${ }^{2}$ Environmental Science and Technology Research Center, Department of Environmental Health Engineering, School of Health, Shahid Sadoughi University of Medical \\ Sciences, Yazd, Iran \\ "Corresponding author: Ali Asghar Ebrahimi, Environmental Science and Technology Research Center, Department of Environmental Health Engineering, School of Health, \\ Shahid Sadoughi University of Medical Sciences, Postal Code: 8915173160, Iran, Tel: +98-3538209100-14, Fax: +98-3538209111, E-mail: ebrahimi20007@gmail.com
}

Received 2016 June 06; Revised 2016 November 13; Accepted 2016 December 15.

\begin{abstract}
Background: Leachate contains a large amount of pollutants that make it very complicated and expensive for treatment. Hence, leachate treatment generally requires various combined processes that must be done carefully.

Objectives: The aim of this study was to determine the sequencing batch reactor (SBR) performance in treatment of composting plant leachate.

Methods: In this experimental study, an aerobic biological SBR with 2 liters capacity was used for treatment of leachate from composting plant of Isfahan, Iran. The organic loading rate (OLR) increased from 0.25 to $6.3 \mathrm{~g}$ COD/L.d in 11 runs during 280 days. To determine the reactor performance, $\mathrm{COD}$, SCOD, rbCOD, $\mathrm{BOD}_{5}, \mathrm{TKN}$, and TP were measured in accordance with standard methods. Finally, the data were analyzed using Excel 2007 software.

Results: In this study, the highest removal efficiency in SBR was obtained at 0.75 to $1.5 \mathrm{~g}$ COD/L.d loading rate. The maximum removal rates for COD, SCOD, rbCOD, and $\mathrm{BOD}_{5}$ were $92.45,93.33,99.8$, and $96 \%$, respectively. The average removal efficiencies for total nitrogen and phosphorus were 73.6 and $66.5 \%$, respectively.

Conclusions: According to the results, SBR performance in the removal of organic matter, nitrogen, and phosphorus at low loading rates is satisfactory, while the removal efficiency decreased by increasing loading rate and decreasing retention time.
\end{abstract}

Keywords: Sequencing Batch Reactor, Treatment, Compost Leachate, Isfahan

\section{Background}

Nowadays, waste production in the world has increased due to population growth, improvement of living standards, economic conditions, and development of industries (1). In Iran, approximately 60 tons of solid waste are produced per day that more than $70 \%$ of them are converted into organic fertilizer. There are different methods for organic waste disposal including landfilling, incineration, composting, and pyrolysis (2). One of these methods is composting in which leachate is produced as 100 liters per ton of waste production (3). Municipal solid waste leachate, a very strong wastewater, contains a large amount of priority pollutants (carcinogens), pathogenic organisms, persistent organic compounds, and heavy metals (4-6). Therefore, special attention should be paid to control, collection, treatment, and disposal of this pollutant, while the lack of an appropriate method for its treatment, collection, and disposal causes severe contamination of soil, groundwater, and surface water to persistent and toxic organic compounds, nitrogen compounds, aromatic and phenolic compounds. Moreover, it threatens human life and aquatic organisms $(7,8)$. Leachate contains a large amount of pollutants which their treatment is very complicated and expensive, and generally requires various and combined processes; therefore, the treatment and disposal of leachate must be done carefully. The appropriate treatment of leachate is also a major problem in different countries. For leachate treatment usually different physical, chemical, and biological methods are used (9). Among the various leachate treatment methods, biological processes have priority due to their lower cost, easy operation, and environmental compatibility $(10,11)$. One of the most common modified conventional activated sludge processes is biological sequencing batch reactor(SBR). This system is used for treatment of municipal and industrial wastewater as well as leachate (12-14). The SBR process includes 5 steps: filling, reaction (aeration), sedimentation, discharge, and rest. All of these steps are done in one reactor with a discontinuous input flow $(10,13,15)$.

In Laitinen et al. (2006) study on landfill leachate treatment using SBR, the concentrations of TSS, $\mathrm{BOD}_{5}$, phosphorus, and ammonia nitrogen in effluent were 475, 1240, 10, and $210 \mathrm{mg} / \mathrm{L}$, respectively (16). Zhou et al. (2006) could remove $93.76 \%$ COD, $98.28 \%$ BOD5, and $84.74 \%$ total nitro- 
gen in landfill leachate treated by SBR (14). A study conducted by Hajiabadi et al. showed that COD removal efficiency was above $97 \%$ for strong synthetic wastewater using SBR (17). Karimi et al. (2011) studied WAO (Wet air oxidation), WPO (Wet peroxide oxidation), and a combination of WAO/GAC (Granular activated carbon) processes for organic matter removal from Isfahan composting factory leachate under different conditions. They found that the combined process had higher efficiency than two other methods, while $\mathrm{BOD}_{5} / \mathrm{COD}$ ratio reached $90 \%$ (7). Amin et al. (2015) studied a complementary treatment of leachate using SBR. Their results demonstrated that COD removal efficiency increased with time in the bioreactor in all experiments and reached up to $70 \%(2)$.

In Isfahan, about $60 \%$ of municipal solid waste is converted into compost that produces almost $50 \mathrm{~m}^{3}$ leachate daily $(18,19)$. Therefore, treatment of this leachate is a key factor in the success of municipal solid waste management in Isfahan. To the best of our knowledge, there is no available paper on determination of SBR performance in treatment of leachate from the composting plant located in Isfahan.

\section{Objectives}

Owing to the high efficiency of SBR and due to leachate problems, the aim of this study was to determine SBR performance in treatment of composting plant leachate.

\section{Methods}

In this experimental study, an aerobic biological SBR with two liters capacity was used for treatment of composting plant leachate in Isfahan, Iran. The samples were taken from leachate inlet to the leachate ponds of Isfahan composting plant. Since, leachate is generated from different parts of composting plant including sections of receiving solid wastes, grinders, wastes compactor, and fermentation site, the sampling was done from final channel in which the leachate is a mixture from different parts of production process of the organic fertilizer plant. The leachate was filtered and diluted and then injected into the SBR reactor after $\mathrm{pH}$ adjustment by caustic soda. The organic loading rate (OLR) increased from 0.25 to $6.3 \mathrm{gCOD} / \mathrm{L}$.d in 11 runs during the 280-day study period. To determine the reactor performance during the period, COD, SCOD, rbCOD, $\mathrm{BOD}_{5}, \mathrm{TKN}$, and TP were measured in accordance with procedures provided in standard methods. In this study, the average amounts of the influent $\mathrm{COD}, \mathrm{BOD}_{5}$, TKN, TP, EC, and $\mathrm{pH}$ were 95.5, 55.2, 2.3, $0.28(\mathrm{~g} / \mathrm{L}), 33.5(\mathrm{~ms} / \mathrm{cm})$, and 4.4, respectively.
After determination of COD: N: $\mathrm{P}$ in the raw leachate, ammonium chloride $\left(\mathrm{NH}_{4} \mathrm{Cl}\right)$ and/or potassium dihydrogen phosphate $\left(\mathrm{KH}_{2} \mathrm{PO}_{4}\right)$ were added, if necessary, to provide the required nitrogen and phosphorus for the biological process. The sludge from aeration basin of municipal wastewater treatment plant in the north of Isfahan was used for seeding the aerobic reactor. During this study, COD, SCOD, rbCOD, $\mathrm{BOD}_{5}$, TKN, and TP parameters were analyzed, while $\mathrm{DO}, \mathrm{pH}$, and temperature parameters were controlled.

\subsection{Specifications of SBR Pilot}

In this study, a combination of anaerobic and aerobic methods including anaerobic reactors (AMBR and ASBR) and aerobic reactors (SBR and SBR-MBR) were used. The data of this study were the measured parameters in input and output of SBR. The SBR was made of plexiglass with $16.5 \mathrm{~cm}$ in diameter and $35.5 \mathrm{~cm}$ in height. Total volume of the reactor was 5 liters that just 2 liters were used, while discharge volume was selected one liter based on the flow rate for subsequent reactors. Each reactor cycle lasted for 24 hours. This process included discharge time (10 minutes), filling time (10 minutes), and sedimentation (60 minutes). The reactor was aerated in the remaining time and equipped with substrate injection tube and effluent discharge pipe. Substrate injection and effluent discharge from the reactor were performed by a peristaltic pump made by Etatron Co, Italy. The reactor was aerated using an air pump connected to the diffuser. To control the function and operation of pumps, an electronic processing system known as programmable logic controller (PLC)Omron Manufacturing Co., Japan, was used (Figure 1).

\subsection{Reactor Operation}

To launch the reactor and reach appropriate COD removal efficiency, reactor operation began with $1 \mathrm{~g} \mathrm{COD} / \mathrm{L} . \mathrm{d}$. The Injection rate was one liter in 24 hours and the amount of dilution gradually reduced; therefore, in the ninth month of operational period, leachate was injected into the reactor without any dilution. In the tenth and eleventh months, the input flow rate increased to two liters and then the reactor performance was evaluated.

The measurement of all parameters was based on standard methods (20). The experiments were done with three replicates to determine the accuracy and precision, and then the results were compared with available data. The accurate data were transferred to Excel 2007 and then the required diagrams were plotted by the software. 


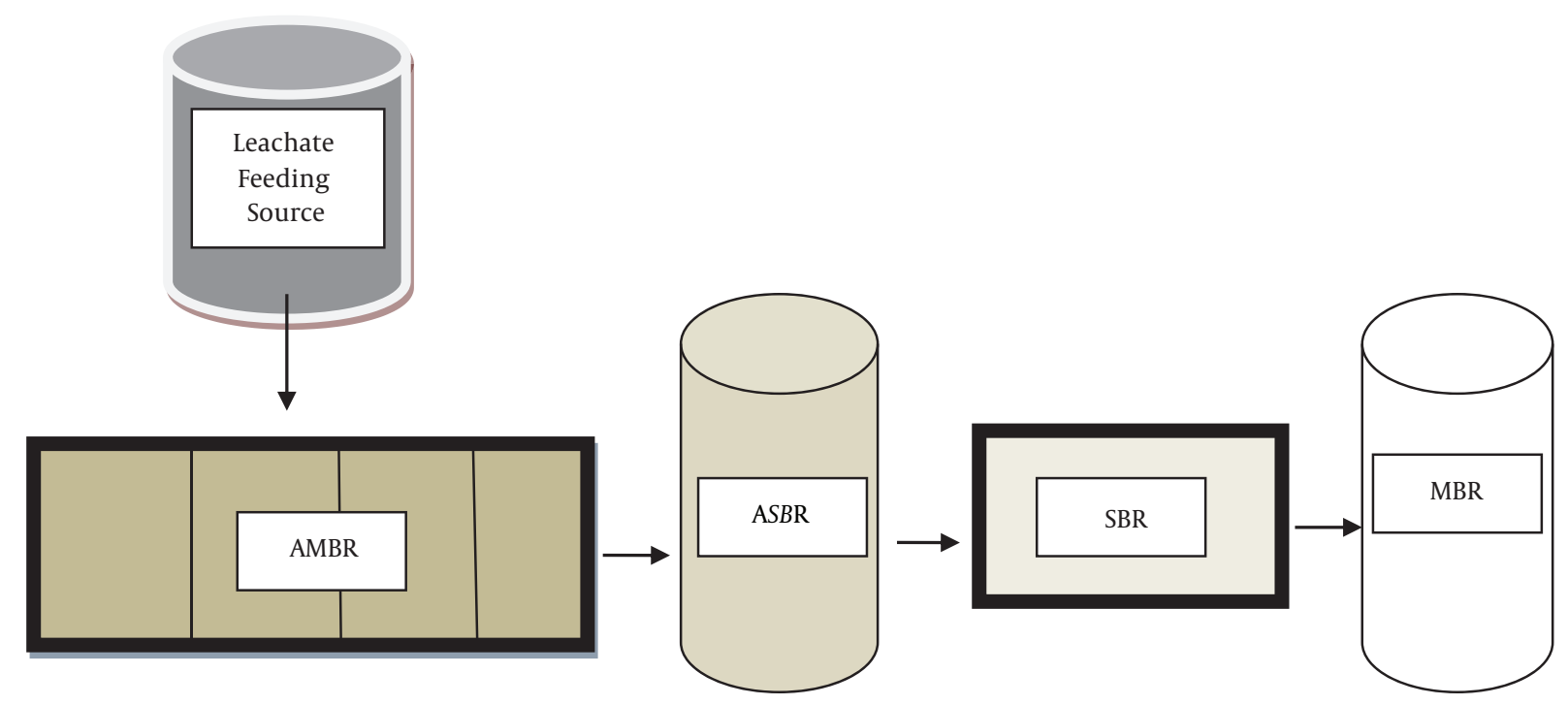

Figure 1. General Schematic of Leachate Treatment Process

\section{Results}

\section{1. $C O D, S C O D, r b C O D$ and $B O D_{5}$}

The average concentrations of COD, SCOD, rbCOD, and $\mathrm{BOD}_{5}$ in different OLRs are shown in Table 1 . The concentrations of these parameters in the input of the reactor were in range of 400 to 6300,100 to 1600,10 to 330 , and 90 to $1,600 \mathrm{mg} / \mathrm{L}$, respectively, while in the output of the reactor, they were in range of 82 to 992,19 to 216,0 to 18.3 , and 12 to $143 \mathrm{mg} / \mathrm{L}$, respectively. In this table, F/M ratio in the different ORLs was in the range of 0.023 to 0.435 day $^{-1}$.

Figure 2 shows the removal efficiencies of COD, SCOD, and $\mathrm{BOD}_{5}$ in different operation periods. When OLR was $0.25 \mathrm{~g} \mathrm{COD} / \mathrm{L} . \mathrm{d}$, the average removal efficiencies of COD and SCOD were $78.2 \%$ and $79.5 \%$, respectively; and when OLR was in range of 0.75 to $1.55 \mathrm{~g}$ COD/L.d, they were $92.4 \%$ and $93.3 \%$, respectively. In addition, by increasing OLR up to 6.3 g COD/L.d, average COD and SCOD removal efficiencies decreased to $84.3 \%$ and $85.6 \%$, respectively.

\subsection{Total Nitrogen and Phosphorus}

The concentrations of total nitrogen and phosphorus in the input and output of the SBR at different organic loading rates are shown in Table 2 . In this study, the concentrations of total nitrogen and phosphorus in the input of the reactor at OLR of $0.25 \mathrm{~g}$ COD/L.d were 122.12 and 27.57 $\mathrm{mg} / \mathrm{L}$ and in the output of the reactor were 37.25 and 14.11 $\mathrm{mg} / \mathrm{L}$, respectively. The concentrations of total nitrogen and phosphorus in the input of the SBR at OLR of $6.3 \mathrm{~g}$ COD/L.d were 1443.4 and $217.26 \mathrm{mg} / \mathrm{L}$ and in the output of the reactor were 477.76 and $69.52 \mathrm{~m} / \mathrm{L}$, respectively.

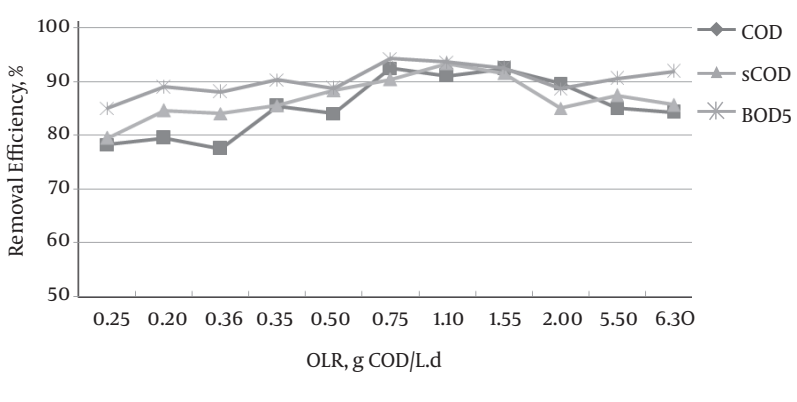

Figure 2. Average Removal Efficiencies of $\mathrm{COD}, \mathrm{SCOD}$ and $\mathrm{BOD}_{5}$ in the SBR

Figure 3 shows the concentrations of total nitrogen and phosphorus in SBR reactor in different OLRs. According to the results, the minimum and maximum removal efficiencies for total nitrogen were $65.5 \%$ and $79.6 \%$ (mean $=73.6 \%$ ), respectively, while for total phosphorus they were $71.4 \%$ and $59.6 \%$ (mean $=66.5 \%$ ), respectively. The results showed that by increasing OLR and decreasing hydraulic retention time (HRT), the removal efficiency of these parameters decreased.

\section{Discussion}

\subsection{COD, SCOD, rbCOD and BOD5}

Based on the results, the average concentrations of COD, SCOD, rbCOD, and $\mathrm{BOD}_{5}$ in the first period of operation at $0.25 \mathrm{~g} \mathrm{COD/L.d} \mathrm{loading} \mathrm{rate} \mathrm{were} \mathrm{500,} \mathrm{100,} \mathrm{10,} \mathrm{and}$ 
Table 1. The Average Concentration of COD, SCOD, rbCOD, and $\mathrm{BOD}_{5}$ in the Input and Output of the SBR

\begin{tabular}{|c|c|c|c|c|c|c|c|c|c|c|c|}
\hline \multirow[t]{2}{*}{ Time, d } & \multirow[t]{2}{*}{ Level } & \multirow[t]{2}{*}{ OLR, gCOD/L.d } & \multicolumn{2}{|c|}{ COD, $\mathrm{mg} / \mathrm{L}$} & \multicolumn{2}{|c|}{ SCOD, $\mathbf{m g} / \mathbf{L}$} & \multicolumn{2}{|c|}{ rbCOD, mg/L } & \multicolumn{2}{|c|}{ BOD5, mg/L } & \multirow[t]{2}{*}{$F / M(1 / d)$} \\
\hline & & & Input & Output & Input & Output & Input & Output & Input & Output & \\
\hline 1-37 & 1 & 0.25 & $500 \pm 75$ & $109 \pm 14$ & $100 \pm 15$ & $21 \pm 5$ & $10 \pm 2$ & 0 & $90 \pm 27$ & $14 \pm 3$ & 0.023 \\
\hline $38-46$ & 2 & 0.20 & $400 \pm 50$ & $82 \pm 25$ & $120 \pm 18$ & $18 \pm 6.5$ & $21 \pm 4$ & 0 & $110 \pm 28$ & $12 \pm 2$ & 0.028 \\
\hline $47-59$ & 3 & 0.36 & $720 \pm 100$ & $162 \pm 32$ & $180 \pm 27$ & $29 \pm 7$ & $20 \pm 4$ & 0 & $200 \pm 50$ & $24 \pm 6$ & 0.053 \\
\hline $60-74$ & 4 & 0.35 & $700 \pm 110$ & $102 \pm 13.5$ & $130 \pm 20$ & $19 \pm 5.5$ & $20 \pm 5$ & 0 & $190 \pm 42$ & $19 \pm 5$ & 0.052 \\
\hline $75 \cdot 98$ & 5 & 0.50 & $1000 \pm 160$ & $160 \pm 35.4$ & $330 \pm 50$ & $39 \pm 8$ & $30 \pm 7$ & 0 & $120 \pm 34$ & $14 \pm 3$ & 0.035 \\
\hline $99-128$ & 6 & 0.75 & $1500 \pm 260$ & $114 \pm 27$ & $290 \pm 44$ & $28 \pm 7.5$ & $20 \pm 5$ & 0 & $400 \pm 120$ & $23 \pm 4$ & 0.100 \\
\hline $129-159$ & 7 & 1.10 & $2200 \pm 440$ & $198 \pm 55$ & $420 \pm 63$ & $32.5 \pm 8$ & $80 \pm 21$ & 0 & $500 \pm 100$ & $32 \pm 7$ & 0.118 \\
\hline $160 \cdot 189$ & 8 & 1.55 & $3100 \pm 470$ & $239 \pm 60$ & $610 \pm 92$ & $52 \pm 22$ & $100 \pm 27$ & $12 \pm 2.5$ & $300 \pm 72$ & $23 \pm 4$ & 0.089 \\
\hline $190-248$ & 9 & 2.00 & $4000 \pm 1200$ & $416 \pm 125$ & $1100 \pm 165$ & $165 \pm 25$ & $100 \pm 27$ & $13.5 \pm 2.2$ & $1000 \pm 260$ & $114 \pm 16$ & 0.250 \\
\hline $249 \cdot 263$ & 10 & 5.50 & $5500 \pm 770$ & $825 \pm 115$ & $1600 \pm 240$ & $202 \pm 42$ & $100 \pm 27$ & $16 \pm 4.1$ & $1500 \pm 270$ & $143 \pm 23$ & 0.417 \\
\hline \multirow[t]{3}{*}{$264-279$} & 11 & 6.30 & $6300 \pm 1070$ & $992 \pm 155$ & $1500 \pm 225$ & $216 \pm 45$ & $100 \pm 27$ & $18.30 \pm 4.3$ & $1600 \pm 320$ & $131 \pm 26$ & 0.435 \\
\hline & \multicolumn{2}{|c|}{ Minimum } & $400 \pm 50$ & $82 \pm 25$ & $100 \pm 15$ & $19 \pm 5.5$ & $10 \pm 2$ & 0 & $90 \pm 27$ & $12 \pm 2$ & 0.023 \\
\hline & \multicolumn{2}{|c|}{ Maximum } & $6300 \pm 1070$ & $992 \pm 155$ & $1600 \pm 240$ & $216 \pm 45$ & $330 \pm 69$ & $18.30 \pm 4.3$ & $1600 \pm 320$ & $143 \pm 23$ & 0.435 \\
\hline
\end{tabular}

Table 2. The Concentration of Total Nitrogen and Phosphorus in the Input and Output of the SBR

\begin{tabular}{|c|c|c|c|c|c|}
\hline & & $\begin{array}{l}\text { Time, d } \\
\text { Input }\end{array}$ & $\begin{array}{c}\text { Level } \\
\text { Output }\end{array}$ & $\begin{array}{c}\text { TP, mg/L } \\
\text { Input }\end{array}$ & $\begin{array}{c}\text { TKN, mg/L } \\
\text { Output }\end{array}$ \\
\hline $1-37$ & 1 & $11.14 \pm 5.5$ & $27.57 \pm 5.8$ & $37.25 \pm 9.5$ & $122.12 \pm 30.53$ \\
\hline $38-46$ & 2 & $12.01 \pm 5.7$ & $32.29 \pm 8$ & $34.68 \pm 9$ & $141.55 \pm 31.2$ \\
\hline 47-59 & 3 & $10.16 \pm 4.8$ & $30.48 \pm 8.6$ & $70.13 \pm 25.6$ & $265.64 \pm 53.1$ \\
\hline $60-74$ & 4 & $11.36 \pm 5$ & $31.09 \pm 10$ & $68.92 \pm 28.3$ & $282.47 \pm 50.9$ \\
\hline $75-98$ & 5 & $25.24 \pm 8$ & $78.24 \pm 27.4$ & $106.60 \pm 33$ & $493.54 \pm 78.9$ \\
\hline $99-128$ & 6 & $30.23 \pm 9.5$ & $98.47 \pm 32.5$ & $142.49 \pm 27.8$ & $698.46 \pm 69.9$ \\
\hline $129-159$ & 7 & $36.85 \pm 10.6$ & $113.10 \pm 31.7$ & $172.99 \pm 35$ & $4816.00 \pm 122.4$ \\
\hline $160-189$ & 8 & $42.13 \pm 712$ & $147.30 \pm 26.5$ & $308.96 \pm 55.4$ & $1197.50 \pm 215.6$ \\
\hline $190-248$ & 9 & $49.12 \pm 15.5$ & $154.62 \pm 30.2$ & $380.90 \pm 76$ & $1354.06 \pm 338.5$ \\
\hline $249-263$ & 10 & $57.10 \pm 18$ & $172.00 \pm 36.2$ & $462.72 \pm 72.6$ & $1341.21 \pm 388.9$ \\
\hline $264-279$ & 11 & $69.52 \pm 20.5$ & $217.26 \pm 54.4$ & $477.76 \pm 75.5$ & $1443.40 \pm 461.9$ \\
\hline
\end{tabular}

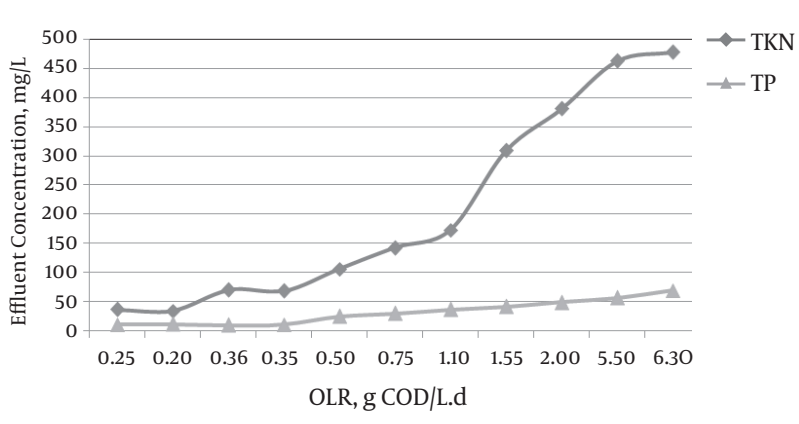

Figure 3. The Concentration of Total Nitrogen and Phosphorus in the Output of the SBR
$90 \mathrm{mg} / \mathrm{L}$ in the input and 109, 21, 0 , and $14 \mathrm{mg} / \mathrm{L}$ in the output, respectively. The removal percentages of these parameters were 78.2, 79.5, 89.6, 86.3\%, respectively. An increase in the concentration of these parameters in the input and output of the reactor was observed with increasing OLR of the reactor. As Figure 2 shows, the maximum removal percentage was achieved when OLR was in the range of 0.75 to $1.5 \mathrm{~g} \mathrm{COD} / \mathrm{L} . d$. The maximum removal rates of these parameters were $92.4,93.33,99.8$, and $96 \%$, respectively, in the same loading rate. In this loading rate, the concentrations of COD, SCOD, rbCOD, and $\mathrm{BOD}_{5}$ in the effluent of the reactor were 110, 28, 0, and $23 \mathrm{mg} / \mathrm{L}$, respectively. During the ninth month of operation in which the reactor was loaded with non-diluted leachate, the removal efficiencies of COD, SCOD, rbCOD and $\mathrm{BOD}_{5}$ were $89.6,85,98.9$, and $92 \%$, respec- 
tively, while their concentrations in the effluent of the reactor were $420,165,0$, and $114 \mathrm{mg} / \mathrm{L}$, respectively.

It was also observed that by increasing OLR, the removal efficiency decreased so that by doubling the OLR(in the tenth and eleventh month of operation period), the removal efficiency decreased again.

At $6.3 \mathrm{~g} \mathrm{COD/L.d} \mathrm{loading} \mathrm{rate,} \mathrm{the} \mathrm{concentrations} \mathrm{of}$ COD, SCOD, rbCOD, and $\mathrm{BOD}_{5}$ in the input were 6300,1500 , 330 , and $1600 \mathrm{mg} / \mathrm{L}$, while their concentrations reached to $990,216,11$, and $131 \mathrm{mg} / \mathrm{L}$ in the output giving $84.25,85.6,98$, and $91.8 \%$ removal efficiencies, respectively. Comparison of these results with the standards of effluent discharge to the environment shows that the SBR operated at 0.75 to $1.5 \mathrm{~g} \mathrm{COD/L.d} \mathrm{loading} \mathrm{rate} \mathrm{can} \mathrm{comply} \mathrm{with} \mathrm{the} \mathrm{allow-}$ able limits for discharging the effluent; nonetheless, there are some limitations for all the parameters by increasing loading rate to double. Therefore, the removal efficiencies of the above mentioned parameters decreased by increasing OLR and decreasing HRT. The F/M ratio which was 0.023 day $^{-1}$ at $0.25 \mathrm{~g}$ COD/L.d loading rate also changed with different loading rates. By increasing $\mathrm{BOD}_{5}$ concentration in the input, the $\mathrm{F} / \mathrm{M}$ ratio increased to $0.25 \mathrm{day}^{-1}$ in the ninth month of operation at $2 \mathrm{~g} \mathrm{COD/L.d} \mathrm{loading} \mathrm{rate;} \mathrm{when} \mathrm{no}$ dilution was applied, the ratio increased to 0.43 day $^{-1}$ by doubling flow rate and increasing OLR to $6.3 \mathrm{~g}$ COD/L.d. The results of Zhou et al. (2006) study on landfill leachate treatment by SBR indicated that the average removal efficiencies of $\mathrm{BOD}_{5}$ and COD were $98 \%$ and $94 \%$, respectively (14). While in our study, the average removal efficiencies of $\mathrm{BOD}_{5}$ and COD were lower due to the presence of interfering matters in the leachate such as nitrogen compounds, volatile fatty acids, heavy metals, ammonium, toxic, and pharmaceutical substances which inhibit biological activity. Hajiabadi et al. (2009) showed that COD removal efficiency was above $97 \%$ in treatment of strong synthetic wastewater in SBR reactor in different cell residence times (CRT). Their results also showed that F/M ratio was in the range of 0.42 to 0.79 day $^{-1}$ and the amount of MLSS was $3,200 \mathrm{mg} / \mathrm{L}$. They also found that by decreasing HRT, the removal efficiency decreases (21). El-Fadel et al. (2004) studied the treatment of landfill leachate by SBR system. The results showed that the COD removal was in the range of 75.9 to $99.8 \%$ (22). In a study on WAO, WPO, and a combination of WAO/GAC processes for organic matter removal from leachate of Isfahan composting factory under different conditions carried out by Ehrampoush et al. (2011), the results showed that the combined process had higher efficiency than two other methods while $\mathrm{BOD}_{5} / \mathrm{COD}$ ratio was achieved as 90\% (7). Diamadopoulos et al. (1997) showed that $\mathrm{BOD}_{5}$ and COD removal efficiencies in the treatment of mixed landfill leachate and domestic sewage in SBR were 98.7\% and 85.5\%, respectively (23). Schwarzenbeck et al.
(2005) revealed that SBR system could remove $90 \%$ of COD from dairy wastewater (24). Yoong et al. (2000) investigated the treatment of wastewater containing phenol in SBR and found 97\% COD removal at OLR of 3.12 gCOD/L.d (25). Hashemi et al. (2016) studied an anaerobic migrating blanket reactor (AMBR) for polycyclic aromatic hydrocarbons (PAHs) and heavy metals removal and found that the AMBR process presented high removal efficiencies in removal of COD, especially when OLR was lower than $4 \mathrm{~g}$ COD/L.d (6). Amin et al. (2015) investigated a complementary process for leachate treatment using SBR. They found that COD removal efficiency increased in the bioreactor with time in all the experiments and reached up to 70\% (2).

The results of this study on removal efficiencies are consistent with the results of other studies, while in some cases our reactor showed lower performance probably due to the nature of leachate and presence of various impurities and pollutants.

\subsection{Total Nitrogen and Phosphorus}

In this study, the average removal percentage of phosphorus in the SBR was 66.5\%. The removal efficiency increased from 59.6 to $71.4 \%$ by increasing OLR from 0.25 to $1.5 \mathrm{~g}$ COD/L.d; then, it decreased to $68 \%$ when OLR increased to $6.3 \mathrm{~g} \mathrm{COD/L.d;} \mathrm{this} \mathrm{was} \mathrm{because} \mathrm{by} \mathrm{doubling}$ the input flow rate HRT decreased in this loading rate. For phosphorus removal, at first it needs anaerobic condition followed by aerobic condition. In our study, this sequence may not happen well. Total nitrogen removal efficiency was higher than phosphorus removal efficiency. Average total nitrogen removal efficiency was $73.6 \%$. In the present study, the anoxic condition perhaps did not happen; therefore, denitrification and consequently nitrogen removal did not happen well. El-Fadel et al. (2004) investigated the treatment of landfill leachate by SBR process. The results showed that ammonia nitrogen removal rate was in range of 31 to $99.8 \%$ (22). Spagni et al. (2009) showed 95\% nitrogen removal efficiency for treatment of an old landfill leachate by SBR system (26). The nitrogen removal efficiency for treatment of mixed landfill leachate and domestic sewage in the SBR based on Diamadopoulos et al. (1997) study was 50\% (23). The dairy wastewater treatment in SBR employed by Schwarzenbeck et al. (2005) showed that the removal efficiencies of TKN and TP were $80 \%$ and 67\%, respectively (24). Chong and Flinders (1999) showed 50 to $90 \%$ phosphorus removal efficiency for treatment of municipal wastewater by SBR (27). The results of Hamamoto et al. (1997) study on the treatment of wastewater by SBR showed that the average nitrogen and phosphorus removal rates of $86 \%$ and $82 \%$ were achieved in the pilot plant and 96\% and 93\% in the full-scale plant, respectively (28). Zhou et al. (2006) studied a laboratory-scale SBR for 
treatment of landfill leachate containing high concentration of ammonium nitrogen with municipal fecal supernatant. Their results indicated that the average removal efficiency of TKN was $85 \%$. They also found that there is a stable simultaneous nitrification and denitrification in this system (14). In some cases, the removal percentages obtained in this study were in agreement with the results obtained in some studies, while they were in contrast to some others. It should be noted that leachate nature is different from wastewater nature used in some previous studies. Since the required C: N:P for operating an aerobic system is 100: $5: 1$, this ratio was controlled in this study that showed no violation. Therefore, there is a possibility for leachate treatment using this biological method which is environmentally acceptable.

\subsection{Conclusions}

The results of this study revealed that the best performance of the SBR was observed in the range of 0.75 to 1.5 g COD/L.d loading rate. The maximum removal rates for COD, SCOD, rbCOD, and BOD 5 were 92.45, 93.33, 99.8, and $96 \%$, respectively. The average removal efficiencies of total nitrogen and phosphorus were 73.6 and 66.5\%, respectively. According to the results, we can conclude that the performance of SBR in the removal of organic matter, nitrogen, and phosphorus in low OLR was satisfactory and the removal efficiency decreased by increasing OLR and decreasing HRT. On the other hand, this technique had some disadvantages such as: 1 . The presence of toxic substances and metals can cause disturbance in the removal of nitrogen and phosphorus, 2. $\mathrm{pH}$ of the leachate was low that needs pH adjustment; 3 . System was difficult to operate, 4. There was an unpleasant smell during the operation and, 5. High dilution was required for measurement of the parameters.

\section{Acknowledgments}

The authors thank Isfahan University of Medical Sciences and waste management organization of Isfahan municipality.

\section{Footnotes}

Authors' Contribution: Please clarify and write who was responsible for: study concept and design: Ali Asghar Ebrahimi; acquisition of data: Hassan Hashemi; analysis and interpretation of data: Tahereh Jasemi Zad; drafting of the manuscript: Zahra Derakhshan.

Financial Disclosure: This study was not financially supported.

\section{References}

1. Amin MM, Ebrahimi A, Bina B, Mokhtari M, Hashemi H, Samaei MR, et al. Prediction of the energy content of the municipal solid waste. Int J Environ Health Engin. 2012;1(1):45. doi: 10.4103/2277-9183.105344.

2. Hashemi H, Pourzamani HR, Amin MM, Bina B, Ebrahimi A, Ebrahimi A. Complementary treatment of leachate using sequencing batch reactor. Int J Health System Disaster Manag. 2014;2(4):216. doi: 10.4103/2347-9019.144403.

3. Chang JI, Tsai JJ, Wu KH. Composting of vegetable waste. Waste Manag Res. 2006;24(4):354-62. doi: 10.1177/0734242X06065727. [PubMed: 16941994].

4. Karimi B, Ehrampoush MH, Ebrahimi A, Mokhtari M. The study of leachate treatment by using three advanced oxidation process based wet air oxidation. Iran J Environ Health Sci Engin. 2013;10(1):1.

5. Ghaly AE, Kamal MA, Mahmoud NS, Cote R. Treatment of Landfill Leachate using Limestone/Sandstone Filters Under Aerobic Batch Conditions. Am J Environ Sci. 2007;3(2):43-53. doi: 10.3844/ajessp.2007.43.53.

6. Hashemi H, Ebrahimi A, Mokhtari M, Jasemizad T. Removal of PAHs and heavy metals in composting leachate using the anaerobic migrating blanket reactor (AMBR) process. Desalin Water Treat 2016;57(52):24960-9. doi:10.1080/19443994.2016.1144529.

7. Ehrampoush MH, Mokhtari M, Ebrahimi A. Comparisons of Three Advanced Oxidation Processes in Organic Matter Removal from Esfahan Composting Factory Leachate. Iran J Health Environ. 2011;4(2):149-58.

8. Kurniawan TA, Lo WH, Chan GYS. Degradation of recalcitrant compounds from stabilized landfill leachate using a combination of ozone-GAC adsorption treatment. J Hazard Mater. 2006;137(1):443-55. doi: 10.1016/j.jhazmat.2006.02.020.

9. Salem Z, Hamouri K, Djemaa R, Allia K. Evaluation of landfill leachate pollution and treatment. Desalination. 2008;220(1-3):108-14. doi: 10.1016/j.desal.2007.01.026

10. Takdastan A, Mehrdadi N, Azimi AA, Torabian A, Bidhendi GN. Investigation of intermittent chlorination system in biological excess sludge reduction by sequencing batch reactors. J Environ Health Sci Engin. 2009;6(1):53-60.

11. Takdastan A, Pazoki M. Study of biological excess sludge reduction in sequencing batch reactor by heating the reactor. Asian J Chem. 2011;23(1):29.

12. Mahvi AH. Sequencing batch reactor: a promising technology in wastewater treatment. J Environ Health Sci Engin. 2008;5(2):79-90.

13. Eslami H, Talebi Hematabadi P, Ghelmani SV, Salehi Vaziri A, Derakhshan Z. The Performance of Advanced Sequencing Batch Reactor in Wastewater Treatment Plant to Remove Organic Materials and Linear Alkyl Benzene Sulfonates. Jundishapur J Health Sci. 2015;7(3) doi: 10.17795/jjhs-29620.

14. Zhou SQ, Zhang HG, Shi Y. Combined treatment of landfill leachate with fecal supernatant in sequencing batch reactor.J Zhejiang Univ Sci B. 2006;7(5):397-403. doi:10.1631/jzus.2006.B0397.

15. Pazoki M, Takdastan A, Jaafarzadeh N. Investigation of minimization of excess sludge production in sequencing batch reactor by heating some sludge. Asian J Chem. 2010;22(3):1751.

16. Laitinen N, Luonsi A, Vilen J. Landfill leachate treatment with sequencing batch reactor and membrane bioreactor. Desalination. 2006;191(13):86-91. doi: 10.1016/j.desal.2005.08.012.

17. Hashemi H. Increasing of leachate quality using an integrated aerobic membrane bioreactor. J Adv Environ Health Res. 2015;3(1).

18. Ehrampoush MH, Mokhtari M, Karimi B, Ebrahimi A, Amin MM. Catalytic oxidation of hydrogen peroxide and the adsorption combinatory process in leachate waste pretreatment from compost ing factory. Int J Environ Health Engin. 2012;1(1):15. doi: 10.4103/22779183.94399. 
19. American Public Health Association. Standard methods for the examination of water and wastewater. 2. American Public Health Association; 1915.

20. American Public Health Association. Standard Methods for the Examination of Water and Wastewater. ; 2005.

21. Hajiabadi $\mathrm{H}$, Moghaddam MR, Hashemi SH. Effect of sludge retention time on treating high load synthetic wastewater using aerobic sequencing batch reactors. ; 2010

22. El-Fadel M, Bou-Zeid E, Chahine W. Landfill evolution and treatability assessment of high-strength leachate from msw with high organic and moisture content. Int JEnviron Stud. 2003;60(6):603-15. doi: $10.1080 / 0020723032000069187$.

23. Diamadopoulos E, Samaras P, Dabou X, Sakellaropoulos G. Combined treatment of landfill leachate and domestic sewage in a sequencing batch reactor. Water Sci Technol. 1997;36(2-3):61-8. doi: 10.1016/s02731223(97)00370-3.

24. Schwarzenbeck N, Borges JM, Wilderer PA. Treatment of dairy efflu- ents in an aerobic granular sludge sequencing batch reactor. Appl Microbiol Biotechnol. 2004;66(6):711-8. doi:10.1007/s00253-004-1748-6.

25. Yoong ET, Lant PA, Greenfield PF. In situ respirometry in an SBR treating wastewater with high phenol concentrations. Water Res. 2000;34(1):239-45. doi:10.1016/s0043-1354(99)00142-6.

26. Spagni A, Marsili-Libelli S. Nitrogen removal via nitrite in a sequencing batch reactor treating sanitary landfill leachate. Bioresource Technol. 2009;100(2):609-14. doi:10.1016/j.biortech.2008.06.064.

27. Chong R, Flinders A, Krogh C, Battyesmith W, Emmanual A. Retrofitting of intermittent decanted extended aeration (idea) plant for enhanced biological phosphorus removal. Water Sci Technol. 1999;39(6):151-8. doi: 10.1016/s0273-1223(99)00134-1.

28. Hamamoto Y, Tabata S, Okubo Y. Development of the intermittent cyclic process for simultaneous nitrogen and phosphorus removal. Water Sci Technol. 1997;35(1):145-52. doi: 10.1016/s0273-1223(96)008906 . 